\title{
INFLUENCIA DE LAS DIFERENCIAS CULTURALES EN LA RELACION DE AYUDA
}

\section{MARIA JOSE ESCARTIN CAPARROS}

Profesora titular de Trabajo Social

De la EUTS de Alicante

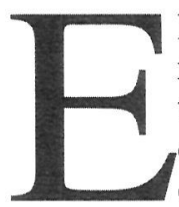

1 contenido fundamental de este artículo pretende poner de manifiesto la relevancia que tiene el elemento cultural, entendido en sentido amplio, cuando el trabajador social de casos actúa con sus clientes. Más en particular, se trata de explicar cómo y por qué el conocimiento o desconocimiento, tanto por parte del profesional como por parte del cliente, de los marcos culturales de uno y otro, pueden afectar a la relación de ayuda.

Teniendo presente que la intervención del trabajador social con su cliente tiene lugar en una relación interpersonal, que es mucho más que un intercambio ocasional entre ambos, esa intervención constituye el núcleo base del conocimiento del trabajo social y supone históricamente el primer nivel de intervención, tanto desde la teoría como desde la práctica profesional.

Los elementos imprescindibles para comprender cómo se desarrolla esta interacción son, en síntesis, los siguientes:

- La formación de un sistema de acción.

- Una determinada naturaleza de las relaciones.

- Un modo específico de comunicación, aparte de unas destrezas o habilidades que aumentan la intensidad y la calidad de las relaciones y de la comunicación y que giran, fundamentalmente, en torno a la entrevista.

Entiendo que una consideración más detenida de cada uno de estos elementos puede ayudar a encuadrar convenientemente nuestro tema de exposición.

\section{LA FORMACION DE UN SISTEMA DE ACCION}

Un sistema de acción se forma con motivo del trabajo que se debe desarrollar y porque las tareas a realizar requieren más de una persona.

El trabajador social aporta a la relación de ayuda un conocimiento básico y una serie de valores y habilidades profesionales para la ayu- 
$\mathrm{da}$; una experiencia personal de vida integrada por elementos culturales, creencias, etc.; su yo total para ser usado por el cliente, si es apropiado a las necesidades de la relación profesional, así como su capacidad personal y profesional ${ }^{1}$.

Todos estos elementos entran en relación con el propio bagaje cultural, situacional, etc. del cliente, que también aporta a la relación sus necesidades o problemas, su percepción acerca de su situación y en definitiva, sus experiencias vitales que influyen en esa percepción y su capacidad para asegurar la situación de conflicto; también aporta fuerzas motivacionales para trabajar en su problema o para el cambio de sí mismo o de su situación.

Esto tiene lugar en un contexto determinado o medio que se desarrolla con motivo de la ayuda que solicita el cliente para superar su situación de necesidad.

En el trabajo que ambos han de realizar — trabajador social y cliente-, los roles de uno y otro emergen de lo que cada uno aporta a esa relación.

El primer encuentro es crucial para la formación del sistema de acción, determinando en gran manera lo que puede suceder en las siguientes sesiones.

La naturaleza de la interacción, su clase y calidad, empieza por formarse en ese primer encuentro entre trabajador social y cliente. Este podrá tomar decisiones en la medida en que el trabajador social pueda responder a su necesidad de ayuda, en la medida en que pueda inspirarle confianza o en la medida de su capacidad para comprender la situación.

El primer contacto tiene lugar en el momento en que la persona acude a una institución para pedir ayuda en relación a una necesidad o problema, para sí mismo o para otra persona: o cuando el trabajador social toma la iniciativa para ayudar a alguien, aunque esa persona no lo haya solicitado (por ejemplo, en el caso de un menor en el que, a través de maestros, vecinos, etc., se le detectan malos tratos).

En el primer caso, estamos frente a un cliente voluntario, en el segundo caso, ante un cliente forzoso. Según sea el tipo de cliente, el trabajador social va a encontrarse con unas dificultades específicas, además de las comunes que implica la formación de un sistema de acción.

En cualquier caso, el trabajador social deberá intentar que el cliente se sienta lo más confortable posible, estimulando un clima apropiado para que se produzca la relación de ayuda.

Es importante, además que el trabajador social muestre al cliente lo que sucederá en el trabajo que van a realizar juntos, lo más pronto y claramente posible.

1 Munro, A. et al., Counselling: the skills of problem-solving, Routledge, Londres, 1990. 
Esto lo hace el trabajador social:

1. Estando atento a lo que el cliente está diciendo y siendo receptivo a sus sentimientos.

2. Demostrando un deseo real de ayudar al cliente, dándole además, alguna indicación de que sabe cómo hacerlo.

3. Preguntando activamente al cliente para compartir sus percepciones acerca de la situación.

4. Esforzándose en comprender los sentimientos o dudas que el cliente no puede expresar verbalmente, estimulándole a que las verbalice para que pueda así comprender mejor su situación.

5. Explicando claramente, desde el principio, de qué manera la institución ofrece sus servicios, la clase de ayuda que puede prestar y los procedimientos para utilizar esa ayuda ${ }^{2}$.

Mientras el trabajador social muestra al cliente cómo pueden trabajar juntos, está obteniendo información y capacitándole para pensar acerca de su situación y ver quizás una nueva perspectiva.

El trabajador social, también en este primer contacto, provoca un clima de confianza, ya que hasta que el cliente puede confiar en él, la relación es débil y la interacción está influida por la preocupación del cliente acerca de la veracidad del profesional. Conforme el cliente experimenta el conocimiento, comprensión y experiencia del trabajador social, generalmente se van reduciendo sus inquietudes y se va estrechando la relación: se está desarrollando un sentimiento de confianza.

Es importante tener en cuenta que en esta fase exploratoria del contacto inicial, el profesional recoge información acerca del cliente en su situación y define las expectativas de éste, tanto acerca del servicio, como de la relación que se va a iniciar.

En este primer encuentro, el trabajador social se muestra no-autoritario, auténtico, receptivo y empático.

Es también en ese momento cuando ambos deciden: a) si pueden trabajar juntos acerca de la necesidad, preocupación o problema del cliente; b) si alguna otra necesidad debe o puede ser tratada; c) si el servicio que necesita el cliente puede ofrecerse mejor desde otra institución y d) si el cliente desea o no continuar el trabajo (algunas veces lo que la persona necesita es discutir su situación con otro y ser escuchado y el hacerlo así le abre nuevas perspectivas y, por tanto, no necesita de posteriores encuentros).

En el caso de que el cliente quiera continuar la relación, ambos - trabajador social y cliente-, necesitan explicitar lo que cada uno espera del otro; los objetivos a cumplir; los roles de cada uno y la

${ }^{2}$ Johnson, L., Social Work Practice. A Generalistic Approach, The South Dakota University Press, Allyn and Bacon, 1987, pág. 171. 
forma en que van a trabajar juntos. Asimismo deben negociar un contrato que regulará la relación.

Edith Ankersmit sugiere que en esta fase, para vencer las resistencias del cliente, es útil hacerle reflexionar sobre dos cuestiones:

¿Por qué estoy aquí? y ¿cómo me siento por estar aquí? ${ }^{3}$.

Esta discusión permitirá al cliente ventilar sentimientos hostiles.

Además, cuando un cliente acude a pedir ayuda, suele estar embargado por sentimientos ambivalentes; por una parte, acude lleno de esperanzas (ser liberado del dolor, ser ayudado, encontrar alguien con quien compartir su problema y que le ayude a soportar la carga, ser amado), pero, por otra parte, está lleno de temores (a que le juzguen, a ser castigado, a ser menospreciado...) ${ }^{4}$.

Ante esto, el profesional, debe procurar comprender y aceptar esos sentimientos, llevando al cliente a la realidad, aclarando lo que de él se puede esperar y aliviando en lo posible los temores y ansiedades del entrevistado.

Ankersmit señala también que es importante reconocer el poder que el trabajador social tiene sobre la situación y, particularmente, resaltar sus límites y el poder que el cliente mantiene: hay que llevar al ánimo de los clientes el hecho de que ellos tienen la responsabilidad de su propia conducta ${ }^{5}$.

La formación del sistema de acción puede hacerse en una o en varias sesiones, dependiendo de la personalidad del cliente, del trabajador social, de los obstáculos que aquél tenga, etc.

Pero la formación de una buena relación es siempre difícil y pueden existir obstáculos que el profesional tiene que reconocer y tener en cuenta.

En primer lugar, la complejidad del funcionamiento humano. Las relaciones entre dos personas con diferentes experiencias de vida y bagajes culturales es particularmente difícil. A menudo se dan malentendidos, prejuicios, prevenciones, etc.

En segundo lugar, los temores de los clientes a los que ya se ha hecho referencia. Estos temores pueden provocar situaciones de enfado $\mathrm{u}$ hostilidad y contribuir a que existan distancias entre las dos partes de la relación.

En tercer lugar, un importante obstáculo es el hecho de que el trabajador social desarrolla su actividad en una organización burocrática. La complejidad de reglas y normas y la dificultad de las organizaciones para individualizar las necesidades de los clientes, a menudo 179.

3 Ankersmit, E., Setting the Contract in Probation, en L. Johnson, ib., pág.

4 Salzberger-Wittemberg, I., La relación asistencial, Amorrortu Ed., Buenos Aires, 1988, págs. 16-17.

5 Ankersmit, E., ib., pág. 177. 
interfieren en la manera en que el profesional provee el recurso que precisa el cliente. Esto puede originar sentimientos de impotencia y frustración en el trabajador social, impidiendo que dé respuestas adecuadas a las necesidades de su cliente.

En cuarto lugar, hay que hacer referencia a la comunicación inadecuada entre ambas partes de la relación.

\section{LA NATURALEZA DE LAS RELACIONES: LA RELACION DE AYUDA}

La relación de ayuda es la cualidad cohesiva del sistema de acción, es el producto de la interacción entre dos personas, siendo un término y un hecho de considerable importancia en la práctica del trabajo social de casos.

A menudo ha sido definida como un «buen rapport» entre el trabajador social y su cliente.

Helen H. Perlman la ha descrito así: «La relación de ayuda es un catalizador, un dinamismo capacitador en el apoyo, crecimiento y liberación de las energías de las personas y de la motivación hacia una solución del problema y el uso de la ayuda» ${ }^{6}$.

Perlman contempla la relación de ayuda como un vínculo emocional y como el medio efectivo para la ayuda. Además, afirma: «la buena relación de ayuda tiene lugar porque provee estímulos y crecimiento... respeta y alimenta la individualidad del otro..., proporciona un sentimiento de seguridad y de identidad» ${ }^{7}$.

Por su parte, Rogers la define como «aquella en la que uno de los participantes intenta hacer surgir, en una o en ambas partes, una mejor apreciación y expresión de los recursos latentes del individuo y un uso más funcional de éstos» ${ }^{8}$.

Esta concepción de la relación de ayuda está fundada, evidentemente, en una fe en las capacidades potenciales que tiene el individuo para cambiar y enfrentarse de forma efectiva a sus conflictos.

Kinget lo expresa de esta manera: «el ser humano tiene la capacidad latente o manifiesta de comprenderse a sí mismo y de resolver sus problemas de modo suficiente para lograr la satisfacción y la eficacia necesarias a un funcionamiento adecuado... El ejercicio de esta capacidad requiere de un contexto de relaciones humanas positivas, favorable a la conservación y a la valoración del "Yo"; es decir, re-

${ }^{6}$ Perlman, H. H., Relationship: The Heart of Helping People, The University of Ch. Press, Chicago, 1978, pág. 2.

7 Perlman, H. H., ib., pág. 24.

${ }^{8}$ Rogers, C., El proceso de convertirse en persona, Paidós, Buenos Aires, 1975, pág. 46. 
quiere relaciones carentes de amenazas o de desafío a la concepción que el sujeto se hace de sí mismo» ${ }^{9}$.

Johnson resume las características de la relación de ayuda:

1. Preocupación por los otros: una actitud que refleja calor, apoyo e interés por el cliente, comunicándole un deseo real de ayudarle en su situación.

2. Compromiso y obligación: consiste en un sentido de responsabilidad por la relación de ayuda.

3. Aceptación: supone una actitud de no juzgar, ausente de crítica por parte del trabajador social, así como una confianza realista en el cliente y respeto por sus sentimientos. Es creer que el cliente puede manejar sus propios problemas y tomar sus decisiones.

4. Empatía: la habilidad para comunicar al cliente que el profesional se preocupa por él y está escuchando sus percepciones y comprendiendo sus sentimientos.

5. Comunicación clara, ausente en lo posible de interferencias.

6. Autenticidad: consiste en la honestidad del profesional en relación consigo mismo y con sus propios sentimientos. Supone habilidad para separar sus problemas y sentimientos de los de su cliente. La honestidad del trabajador social permite al cliente llegar a lo que quiere ser. Esto está presente cuando la comunicación es comprensible y confortable para el cliente.

7. Autoridad y poder: la convicción de que el cliente trabajará para resolver sus propios problemas; esta convicción estimula a la persona por el hecho de pensar que es él el que tiene la autoridad y el poder para resolver su situación. Pero también los conocimientos y habilidades del profesional tienen una base de autoridad y poder.

8. Propósito: la relación de ayuda tiene un propósito conocido y aceptado por ambas partes ${ }^{10}$.

\section{LA COMUNICACION}

La comunicación, evidentemente, es un ingrediente fundamental en la interrelación trabajador social-cliente.

No vamos a entrar aquí a definir qué es la comunicación y de qué forma se realiza pero sí vamos a exponer la importancia de una adecuada comunicación en la relación de ayuda.

En ésta, como en todo acto humano, tan importante es lo que se comunica verbalmente, como el lenguaje corporal. El profesional de-

${ }^{9}$ Kinget, en Rogers, C., Psicoterapia y relaciones humanas, tomo I, Alfaguara, Madrid, 1967, págs. 28-29.

${ }^{10}$ Johnson, L., ib., pág. 176. 
berá estar atento no sólo a lo que dice el cliente a través de las palabras y cómo lo dice, sino también a las conductas no verbales (posturas, gestos, dirección de la vista, tono emocional, pronunciación, etc.).

Hasta aquí hemos visto, algunos de los elementos más importantes a tener en cuenta en la actuación del trabajador social en el trabajo social de casos.

\section{Influencias en la relación de ayuda}

Ahora vamos a analizar las influencias que pueden incidir en la relación.

En efecto, hay varias situaciones en que las características personales del profesional o del cliente tienen especial influencia en el funcionamiento del sistema de acción. Estas situaciones incluyen circunstancias como el hecho de que trabajador social y cliente provengan de grupos sociales, culturales, étnicos o raciales diferentes; o situaciones en las cuales el sexo y la edad pueden afectar la relación y el medio en el cual la acción tienen lugar.

Veamos algunos de estos obstáculos:

- Mutua ignorancia. A causa del desconocimiento acerca de la cultura del otro, tanto por parte del profesional como por parte del cliente, hay una tendencia hacia el estereotipo. El temor hacia el otro también puede ser resultado del desconocimiento o de la incomprensión, llevando a hacer «buenos» o «malos» juicios sin base real. La distancia social no permite el confort y la confianza necesaria para el desarrollo de la relación de ayuda.

- Actitudes hacia otra cultura. Pueden desarrollarse actitudes negativas como consecuencia de experiencias negativas con personas que pertenecen al mismo grupo cultural o étnico que la persona con la que se está trabajando.

- Existencia de diferentes oportunidades, las personas tienen diferentes oportunidades de realización en la vida y el hecho de pertenecer a grupos minoritarios refuerza estas desigualdades. Cuando el profesional no comprende estas diferencias, puede tener expectativas irreales acerca de cómo su cliente pude usar la ayuda que se le ofrece. Esto también puede referirse a los recursos apropiados; algunos recursos no se utilizan por determinados grupos culturales. Por ejemplo, el caso de los transeúntes, con una idiosincrasia especial para contemplar la vida o el cliente educado con fuertes convicciones machistas que tiene muy interiorizado que determinados roles o sentimientos no deben ser expresados por el varón. 
- Conflictos entre expectativas sociales y culturales. A menudo estos conflictos pueden estar presentes, creando ambivalencia en el cliente y si el profesional, por no haber vivido esos conflictos, debido a su status social o cultural, no es consciente de que puede ocurrirle al cliente, estará incapacitado para la ayuda.

Además, los clientes pertenecientes a grupos minoritarios suelen tener un bajo sentimiento de confianza, resultado de sus escasas expectativas para resolver sus problemas, especialmente en lo que se refiere a las necesidades de interrelación, y bajo aprecio de su propia cultura. También tienen diferente noción del tiempo; distinta manera de concebir la cultura masculina y femenina; poca confianza hacia personas de otras culturas y grupos como resultado de relaciones anteriores cargadas de dolor e ira.

Ann Brownlee ha identificado algunas de las diferencias en la cultura que pueden interferir en la relación de ayuda: situaciones inapropiadas para la comunicación de informaciones específicas; tabúes, normas relativas a la intimidad; formas de expresar emociones y sentimientos; manera de expresar aprecio; uso de los silencios; forma y contenido de la comunicación verbal y no verbal y el estilo de persuadir o explicar ${ }^{11}$.

\section{La relación de ayuda y los clientes de minorías étnicas}

Pienso que es importante hacer referencia, en particular, a obstáculos prácticos derivados del encuentro entre trabajadores sociales y clientes de distintas etnia o raza y cultura.

En el medio profesional de los trabajadores sociales se detecta un interés creciente por un hecho hasta ahora casi desconocido en nuestro país, pero habitual en otros países europeos - Gran Bretaña, Francia, Alemania- y en Estados Unidos: el de las migraciones extranjeras.

Aunque el hecho racial no es desconocido para los trabajadores sociales de nuestro país, ya que en nuestra sociedad estamos habituados a convivir con un grupo étnico minoritario: el de los gitanos, instalados casi durante cinco siglos en nuestra sociedad y que representa el $0,56 \%$ de la población total española. Su historia es la historia de una tensión inacabada y constante entre la asimilación a la sociedad y el mantenimiento de la identidad étnica y de su cultura propia ${ }^{12}$.

11 Brownlee, A., Community, Culture and Care, St. Luis, C.V. Morby, 1978, pág. 115.

12 San Román, T. «Las esclusas de la marginación», RTS, 117 (marzo 1990), pág. 21 . 
Sin que el hecho del tiempo que llevan viviendo junto a nosotros, suponga, en principio, una diferencia con respecto a los nuevos emigrantes, en lo que a valoración social o marginación se refiere.

Unos y otros, los gitanos y los nuevos inmigrantes del Tercer Mundo, tienen en común el rechazo, el aislamiento, la pobreza; y ambos sufren, de hecho, segregación.

Y como estos grupos son los que potencialmente tienen más necesidades insatisfechas y menos recursos para salir de su marginación, es lógico que, los gitanos, sean clientes habituales de los Servicios Sociales y que lo sean menos, por desconocimiento o temor a la incomprensión los nuevos inmigrantes.

Sin embargo, son necesarios unos Servicios Sociales, bien sea de Atención Primaria o bien Especializados para atender los numerosos problemas, no sólo de los inmigrantes recién llegados, sino de los que ya están instalados, aunque en este último caso la tendencia es integrarlos en servicios de atención primaria de una red universal de Servicios Sociales ${ }^{13}$.

Algunos datos pueden ayudarnos a comprender el volumen que está tomando la situación y cómo va emergiendo un nuevo grupo de clientes para los trabajadores sociales: el de los inmigrantes de distinta raza y, por tanto, cultura.

España, tradicional país de emigración y ahora también de inmigración, se sitúa cada vez más en las coordenadas políticas y económicas de Europa occidental.

A su vez, las relaciones entre Europa occidental y los países de origen de los inmigrantes (especialmente las ex colonias africanas, asiáticas y americanas) se sitúan en el marco de los intereses dominantes de los países ricos y las aspiraciones de igualdad y desarrollo del Tercer Mundo ${ }^{14}$.

La década de los setenta representa, sobre todo en su segunda mitad, un giro importante en las tendencias migratorias de España. Por un lado, se detiene la emigración hacia Europa e incluso se produce un notable flujo de retornos. Por otro lado, ocurren diversos fenómenos que convierten a España en un país de inmigración ${ }^{15}$.

Y sin embargo, este país, antaño tolerante y puerto de muchas culturas, se vuelve receloso e incluso hostil ante las oleadas de inmigrantes que buscan, fundamentalmente, encontrar en los países ricos, las oportunidades de sobrevivir que en los suyos se les niegan.

Además, a este rechazo social se le ha de añadir el obstáculo legal

13 Alonso, E. «Minorías étnicas, inmigrantes extranjeros, racismo y trabajo social», RTS, 117 (marzo 1990), pág. 99.

14 «Los inmigrantes en España», Documentación Social, 66 (enero-marzo 1987), pág. 71.

15 Los inmigrantes en España, ib., pág. 74. 
de la Ley de Extranjería (1985), tanto por lo que se refiere a su contenido como a su abusiva e indiscriminada aplicación por parte de la Administración. No es aventurada, entonces, la afirmación del Centro de Información para Trabajadores Extranjeros de que «hay una política realmente opresora y de temor hacia esos inmigrantes, encaminada a conseguir que el año 1992 no quede ningún extranjero en situación ilegal y el mínimo posible en situación legal» ${ }^{16}$.

A tenor de las últimas afirmaciones aparecidas en la prensa sobre expulsión de extranjeros, parece que esta suposición no era muy descabellada.

Así, se ven rechazados, expulsados o calificados de delincuentes en un clima de racismo que se disfraza por el hecho de que van a ocupar puestos de trabajo cuando no hay suficientes para los nacionales, recurso fácil que oculta actitudes mucho más hostiles hacia estos pueblos.

En el caso de la inmigración en nuestro país, y según datos oficiales ${ }^{17}$, la procedencia y número de los inmigrantes en España es la siguiente:

- 190.000 hispanoamericanos.

4.000 de Africa negra.

- 95.000 de Africa del Norte, especialmente marroquíes.

- 76.000 portugueses.

- 49.000 filipinos.

- 56.000 otros (fundamentalmente asiáticos y de Oriente Próximo).

- 21.000 apátridas.

Por su especial situación de indefensión y marginación vamos a ocuparnos de los marroquíes, centroafricanos y filipinos, ya que los portugueses, por razón de estar en nuestra misma área geopolítica, y por vecindad, y los hispanoamericanos, por su alta cualificación profesional y nivel cultural sufren menos discriminaciones.

Las características más relevantes de estos grupos son:

- Marroquies: son los inmigrantes más antiguos. De religión musulmana, el $53 \%$ vive con la familia constituida en España, siendo el resto varones, solteros en su mayoría. Suelen recurrir, para solicitar ayuda, principalmente a Cáritas, aunque también buscan ayuda en la solidaridad de su propio grupo.

- Africa Negra: una de las colonias más recientes. En su mayoría son varones, solteros y jóvenes (el $80 \%$ entre 16 y 34

16 «Els Inmigrants Estrangers, exclosos y agredits», Suplements. Cristianisme i justicia, 33 (diciembre 1989), pág. 7.

${ }^{17}$ Els Inmigrants estrangers, «exclosos y agredits», ib., pág. 4. 
años). El hombre es el que sale de su país buscando la independencia económica y familiar, puesto que la mujer ha de permanecer en el clan familiar para el cuidado de los padres, de los ancianos y hermanos ${ }^{18}$.

- Filipinos: generalmente son mujeres que se dedican como internas al servicio doméstico, la mayoría con estudios medios o superiores; este grupo se caracteriza por ser el que demuestra una mayor solidaridad entre ellos para resolver sus propios problemas.

Lo que es común a todos ellos es que el hecho de abandonar el país natal constituye un esfuerzo particularmente difícil, después de haber sufrido experiencias capaces de debilitar la confianza en uno mismo.

El emigrante se marcha de su país porque no gana bastante, o no tiene trabajo. Solamente este hecho le sitúa en el campo de los dominados, con todo lo que esto lleva consigo en términos de desvalorización ${ }^{19}$.

La decisión de irse implica, pues, un esfuerzo doble: en primer lugar, un esfuerzo psicológico para superar la falta de confianza en sí mismo y, en segundo lugar, un esfuerzo para acostumbrarse a una nueva cultura, ritmos diferentes en cuanto sentido del tiempo, lenguaje y usos extraños.

Las relaciones sociales, especialmente entre hombre y mujer, son desconcertantes y constituyen fuentes de tensión; una manifestación de cortesía es recibida como una insolencia y los gestos de simpatía pueden ser mal interpretados.

El tiempo y el espacio urbanos también están reglamentados de manera que el emigrante se encuentra de sobra, con limitaciones que considera lesivas para su libertad personal: no puede celebrar ciertas ceremonias religiosas o familiares (por ejemplo, la fiesta del Cordero), ni hacer ruido a partir de ciertas horas y los olores y ruidos molestan a los vecinos.

Después del desconcierto inicial, generalmente, tratan de imitar el comportamiento de los nativos y compararlo con el propio. Así es como, poco a poco, cada inmigrante inicia un proceso de cambio que acaba por afectar a importantes aspectos de su personalidad y de su identidad cultural.

En el país de acogida, los grupos étnicos en lucha por mantener sus tradiciones y su identidad constituyen auténticas redes de infor-

18 Climent, J. P. y García, M., Emigración extranjera en Barcelona, 44 Informe elaborado por la Comisión de Emigración dependiente del Arzobispado, 1989, pág. 4.

19 Vásquez, A., «La Psicología dels traballadors inmigrants», El Correo de la UNESCO, 89, pág. 26. 
mación sobre trabajos y de defensa de los intereses de la comunidad. Ejemplos de solidaridad interna en muchas ocasiones y de rechazo a los que no pertenecen a las mismas etnias, en otras.

Centrándonos en la relación de ayuda, ya hemos visto cómo las diferencias culturales y raciales pueden interferir en la calidad y naturaleza de aquélla.

En efecto, no podemos cuando hablamos de interacción entre trabajador social y cliente, obviar el impacto de las diferencias culturales y raciales en el desarrollo y uso de la relación profesional.

$\mathrm{S}$. Cooper sostiene que «claramente el racismo penetra profundamente en el inconsciente. Marca a todas sus víctimas - blancos y negros- con profundo dolor, ira, culpa y confusión ${ }^{20}$.

Por esto, Cooper sugiere la conveniencia de que los trabajadores sociales examinen sus creencias con especial atención, así como que «hagan esfuerzos para conocer y tratar con factores raciales, ya que éstos están influidos por fuertes actitudes emocionales» ${ }^{21}$.

Por su parte, Gitterman y Schaeffer, hablando del encuentro entre el profesional blanco y el cliente de color, durante la relación interprofesional, dicen que «una consecuencia directa de las posiciones racistas internalizadas de blancos y negros es la distancia social... como resultado de estas condiciones, surgen dos separadas y distintas experiencias, cada uno es desconocido y extraño para el otro. Es esta cualidad de mutua extrañeza lo que caracteriza el encuentro inicial blanco-negro» ${ }^{22}$.

Esto puede ser desplazado, negado o racionalizado, pero siempre tiene lugar.

Además, antes de que un trabajador social pueda comprender la influencia de la cultura de un cliente determinado, debe comprender su propio cuadro de referencia, así como los grupos dominantes que han influido en esa persona.

Vamos a fijarnos en algunos elementos concretos relacionados con la diferencia racial y cultural y su incidencia en la relación de ayuda:

- El lenguaje.

- La religión.

- La familia y los papeles varón/mujer.

- La manera de solucionar los problemas.

Respecto al primer elemento, hay que observar que, a diferencia de otras profesiones de ayuda que tienen a su disposición tests quími-

${ }^{20}$ Cooper, S., «A look at the effect of racism on clinical social wok», Social Casework, febrero 1978, págs. 54-78.

21 Cooper, S., ib., pág. 60.

22 Gitterman, A. y Schaeffer, A., «The white professional and the black client», Social Casework, 53, mayo 1972, pág. 42. 
cos y biológicos para ayudar a identificar los problemas de los clientes, la práctica del trabajo social se vale exclusivamente del lenguaje, tanto para diagnosticar como para tratar las necesidades y problemas de sus clientes.

El trabajador social depende del discurso del cliente para obtener una información acerca de su problema y de su historia de vida, así como para hacer un diagnóstico social y asesorar indicadores de disfunciones sociales y niveles de desarrollo. El tratamiento del trabajador social en todas sus modalidades está basado en las manifestaciones verbales, tanto por parte del cliente como del trabajador social ${ }^{23}$.

Berta Fantl observa que la comunicación — verbal y no verbalcon una adecuada comprensión de los aspectos subyacentes de la situación bajo la cual la comunicación tiene lugar, es el vehículo para todo tratamiento ${ }^{24}$.

El primer problema, pues, que surge y que interfiere la comunicación entre trabajador social y cliente es cuando ambos pertenecen a grupos étnicos diferentes y cada uno desconoce el lenguaje y los significados del otro. A veces, ocurre que no sólo es el lenguaje, sino otros aspectos de la comunicación, como el ritmo de la conversación y la forma de expresar los hechos y las ideas, lo que incide en ella.

Por ejemplo, Ignacio Aguilar ${ }^{25}$ identifica una diferencia lingüística importante entre trabajadores sociales anglosajones y clientes mejicanos: y es el hecho de la lentitud al hablar. Observan que muchos trabajadores sociales anglosajones no tienen tiempo para las lentas conversaciones que proceden a la identificación del problema del cliente.

Podemos encontrar un paralelismo en el caso de los inmigrantes centroafricanos que no sólo utilizan un ritmo más lento que nosotros, sino que además acostumbra, influidos por su cultura a tener un preliminar e informal intercambio de noticias intrascendentes antes de abordar un problema importante.

Otro tanto ocurre con los marroquíes en los que el problema ya no es la lentitud de su lenguaje, sino el hecho de que tienen la costumbre de utilizar largos preliminares y rodeos antes de abordar una cuestión. Además, suelen utilizar metáforas y parábolas para ilustrar las

23 Portner, E., «Personality development in deaf children», Social Work, 22, junio 1977, págs. 54-57.

${ }^{24}$ Fantl, B., citada por Cormican, John. en «Linguistic Issues in Interwiewing», en Compton, B. y Galaway, B., «Social Work Processes», The Dorsey Press, Chicago, 1984, pág. 288.

25 Aguilar, I., «Initial contracts with mexican-american/american families», Social Work, 17, mayo 1972, págs. 66-70. 
historias, cuestión que puede desconcertar al trabajador social de una ciudad, más inmediatista y pragmático.

En el caso de ambos grupos de emigrantes el hecho antes mencionado tiene que ver también con su sentido del tiempo, diferente al nuestro, que se caracteriza por el vértigo y el apresuramiento.

Además, la comunicación - verbal y no verbal- expresa los sentimientos, ideas y puntos de vista acerca del mundo, desarrollados en un particular contexto cultural. Los significados asignados a la comunicación, entre contextos culturales diferentes, pueden ser incongruentes.

Así, por ejemplo, gestos no verbales tales como los ojos bajos o no mirar a alguien directamente, pueden ser interpretados como signo de respeto y deferencia a la autoridad; mientras que, en otros casos, se pueden interpretar como signos de insinceridad en la persona (por ejemplo, en nuestra cultura, en las normas de urbanidad que se nos inculcan de pequeños se nos dice que hay que mirar abiertamente).

En general, los significados asignados a la comunicación no verbal están más expuestos a las interpretaciones que la comunicación verbal.

La religión es otro factor que, si se desconoce, puede alterar el desarrollo de la relación de ayuda.

En este terreno, evidentemente, las diferencias más notables se encuentran en relación a los practicantes de la religión musulmana, con el agravante de que dentro de ella hay corrientes y niveles de observancia.

Por ejemplo, los marroquíes que vienen a nuestro país pertenecen, en su mayoría, a la corriente sunni y, entre otros condicionantes, la regla coránica marca fuertes diferencias entre hombres y mujeres.

Estas están sujetas a la autoridad paterna y acceden al matrimonio concertado por el padre, pudiendo casarse únicamente con musulmanes, pues la ley coránica exige que el esposo sea de esa condición; no así para el hombre que puede casarse con cristianas o judías.

La religión también impone reglas en la alimentación, como la prohibición de comer cerdo, el ayuno en Ramadán, etc.

Todos estos factores los debe conocer el trabajador social para no sugerir, ni mucho menos obligar a que el cliente haga algo que está prohibido por su religión. Además, tiene que tener en cuenta la connotación fatalista de la religión musulmana, con lo que aquello que a simple vista pudiera parecer apatía para salir de su situación o falta de motivación, no es más que una consecuencia de su especial manera de concebir la vida impuesta por el Corán o la interpretación tradicional de su doctrina.

Respecto a la familia, el trabajo social de casos se ha interesado siempre por ella, en cuanto es la unidad social primaria; sería difícil, 
sin embargo, definir socialmente el comportamiento aceptable o inaceptable de un individuo sin una total comprensión del papel de los padres, tal como está condicionado por los factores culturales ${ }^{26}$.

Especialmente en el caso de centroafricanos y marroquíes, la familia está condicionada por la tradición de clanes y las relaciones de parentesco, notablemente diferentes del modelo occidental ${ }^{27}$.

Respecto a los roles en la familia, los asignados tradicionalmente a hombres y mujeres están fuertemente reforzados, estando la mujer totalmente relegada a un segundo plano, dedicada al cuidado de los niños y debiendo mostrarse reservadas respecto al mundo exterior.

Cuando los hijos van al colegio, por ejemplo, es la madre la que se encarga de recogerlos y llevarlos, siempre silenciosa y a menudo tapada con el chador; mientras que el padre es el que se encarga de todos los aspectos en los que haya que tomar decisiones; entrevistas con maestros o asistentes sociales, etc.

Es importante tener en cuenta que el trabajador social, sobre todo si es varón, no puede dirigirse a la mujer si no es en presencia del marido y no sin antes haberle pedido permiso.

En este aspecto hay una diferencia respecto al colectivo filipino, en el que casi el $90 \%$ son mujeres y con estudios medios o universitarias y con menos problemas a la hora de relacionarse y de tener intercambio con los españoles.

Por último, respecto al uso que los inmigrantes hacen de las instituciones asistenciales, Joan Velasquez y Marilyn McClue sostienen, refiriéndose a las relaciones entre trabajadores sociales anglosajones y clientes negros o chicanos, que existe la convicción de que muchos de esos clientes rehúsan utilizar el servicio o lo abandonan porque no perciben que se les preste ayuda real ni que se den las condiciones óptimas para que se sientan confortables y comprendidos ${ }^{28}$.

Los datos referidos a la población inmigrante en España, según el estudio de Cáritas ${ }^{29}$, muestran que existe un recelo en la utilización de los Servicios Sociales y que, cuando lo hacen, se dirigen preferentemente a instituciones como Cáritas o Cruz Roja, siendo los centroafricanos el colectivo que más utilización hace de ellos, mientras que los filipinos son los que menos buscan esa ayuda.

A este respecto, hay que tener en cuenta que, en su país de origen, la familia extensa es la que se encarga de numerosos aspectos de la

26 Hamilton, G., Teoría y práctica del Trabajo Social de Casos, Ed. La Prensa Médica Mexicana, 1987, pág. 96.

27 Dossier de la Trobada sobre la situació dels inmigrants marroquines, Generalitat de Catalunya, Departament de Benestar Social, 10 de marzo, 1990.

28 Velásquez, J. y McClure, M., A framework for Establishing Social Work Relationships across Racial/Ethnic Lins, en Compton y Galaway, ib., págs. 260265.

29 Situación de los Inmigrantes en España, ib., pág. 67. 
vida cotidiana que en los países industrializados son resueltos por las instituciones. Además, está el factor añadido de la desconfianza; como también evidencia el citado estudio.

\section{Conclusiones}

En general, y para concluir estas ideas, hay que advertir que para que el trabajo sea efectivo, se ha de partir de un amplio conocimiento de base sobre los marcos culturales generales y específicos en que se desenvuelven las personas -así como ser conocedor el trabajador social de los suyos propios-. Además es preciso comprender que, en la actualidad, las culturas se desenvuelven en el marco de una pluralidad ideológica cada vez más creciente.

Los aspectos más concretos que rodean a los temas clave señalados han de ser individualizados y conectado en la práctica profesional de ayuda con una actitud abierta, tolerante y comprensiva que haga posible el establecimiento de una relación auténtica de aceptación y compromiso con el cliente.

Tal actitud permitirá a los trabajadores sociales estar atentos para poder percibir situaciones desde el punto de vista del otro. Además, tienen que ser conscientes de que para ser congruentes con los principios de su profesión, no pueden sustentar prácticas que pudieran discriminar la dignidad de cualquier grupo.

En definitiva, los trabajadores sociales deben tener la firme creencia de que no hay grupos étnicos o culturales mejores o peores, ni superiores o inferiores, sino simplemente diferentes ${ }^{30}$.

Desde este planteamiento universalista y abierto y más allá de cualquier otra consideración de tipo especulativo o retórico, pienso que la opción fundamental de un trabajador social no puede ser otra que el intento de hacer efectiva en la vida práctica de cada día aquella convicción que el filósofo contemporáneo Merleau Ponty supo expresar de forma admirable en esta fórmula precisa: «Una sociedad vale lo que valen en ella las relaciones del hombre con el hombre.»

30 Goodman, J. (ed.), Preface en Goodman, James A., Dynamics of racism, Washington NASSW, 1974, pág. 1. 


\section{BIBLIOGRAFIA}

Alonso, E.: «Minorías étnicas, inmigrantes extranjeros, racismo y trabajo social». RTS, 117 (marzo 1990).

Brownlee, A. T.: Community, Culture and Care, St. Luis, C.V. Morby, 1978.

Compton, B. y Galaway, B.: Social Work Processes. The Dorsey Press, Chicago, 1984.

Cooper, S.: «A look at the effect of racism on clinical work». Social Casework, 22, febrero 1978.

Dossier de la Trobada sobre la situació del inmigrants marroquines. Generalitat de Catalunya, Departament de Benestar Social, 1990.

«Els inmigrants estrangers, "exclosos y agredits"». Cristianisme $i$ Justicia, suplemento 33 (diciembre 1988).

Guitterman, A. y Schaeffer, A.: «The white professional and the black client». Social Casework, 53, mayo 1972.

Johnson, L.: Social Casework Practice. A generalistic approach. The South Dakota University Press, Allyn and Bacon, 1987.

«Los Inmigrantes en España». Documentación Social, 66, enero-marzo 1978.

Munro, A. et al., Counselling: the skills of problem-solving, Routledge, Londres, 1990.

Perlman, H. H.: Relationship: The Heart of Helping People. The University of Chicago Press, Chicago, 1978.

Portner, D. L.: «Personality Development in deaf children». Social Work, 22, enero 1977.

Rogers, C.: El proceso de convertirse en persona, Paidós, Buenos Aires, 1975.

Salzberger-Wittemberg, I.: La relación asistencial, Amorrortu Ed., Buenos Aires, 1988. 